in wild creatures; a caged bird was to him the source of compassion and anger. When the second wife of the late Viscount Grey of Fallodon-Lady Glenconner, renowned for her beauty and her charm -went to Fallodon, she set up there an aviary of exotic and beautiful birds. These birds, having never known freedom, were as contented as the full-winged ducks which haunted Lord Grey's ponds and came to his hand to be fed, some of them even flying on to his head without fear and with great skill. One day Lord Grey, talking of Hudson and of his love of birds, said, pointing to the aviary, "I wonder what Hudson would have thought of this". A pause, and then, with a twinkle in the statesman's eye, he added, "I don't think he would have liked it". Hudson was never satisfied with his books. He once told a great friend of his that he was not pleased even with that classic, "Green Mansions". Yet to many that book is Hudson's best. There are few alive now who remember Hudson, but that small band still recall his rare and forceful personality.

\section{Evolution, Education and Christian Belief}

The British Social Biology Council has performed a useful service in publishing reprints of two important lectures delivered at a conference which it helped to arrange a year ago. In the first booklet, Dr. Julian Huxley pleads for the inclusion of the great generalizations of evolutionary biology in all courses of general education. Some understanding of evolution, he suggests, is indispensable to the answering of the three perennial questions which are always asked by human beings : What are we ? What sort of world do we inhabit, and in what sort of relation do we stand to that world? The teaching of evolution provides the best transition between physicochemical science and the humanities, and, of all branches of knowledge, evolution alone can adequately indicate man's place and destiny in Nature. In the second booklet, Dr. W. H. Thorpe examines the significance of Christianity from the point of view of evolution. Many religious men find it intolerable to accept a belief in natural selection as the main agent of evolutionary change. Dr. Thorpe considers their objections and arrives at the conclusion that "science and a progressive Christian faith are and ever will be indispensable to each other". The reprints may be obtained from the British Social Biology Council, Tavistock House South, Tavistock Square, London, W.C.1, price $1 s$, each.

\section{Scenery in Wales}

By means of an attractively illustrated booklet, the National Museum of Wales has made a praiseworthy attempt to interest Welsh people in the nature and origin of the scenery of their native land. Wales, of course, has such a range of old and new rock-structures that the compilers of the booklet have had some difficulty in deciding what to include. To appeal to as wide an audience as possible they have included commonplace features rather than famous beauty spots; these typical features can be matched in character if not in detail in many parts of Wales. They include the outcrops of limestone and shale exposed on Porthkerry Beach, the weird shapes assumed by ancient volcanic rocks near Trefgarn, alabaster in the Triassic marls in cliffs at Penarth, the peculiar effects of bedding and jointing at the Wash, near Flunston, inclined strata at Broadhaven cliffs, the effect of joints upon the face of $a$ eliff and the way in which pebbles are formed. Other photographs include one of a peat bog, opencast coal-mining, a glaciated valley, the path of a glacier, a meandering river and the formation of stalactites and stalagmites. This attractive and instructive booklet could be widely used in Welsh and other schools; it may be obtained from the Museum, price $2 s .6 d$.

\section{Use of Dermestid Beetles for Cleaning Mammalian Skeletons}

IN the November issue of the Museums Journal, E. M. O. Laurie and J. E. Hill describe the operation of cleaning mammalian skeletons by the use of Dermestid beetles. The species used is Dermestes maculatus, and the colonies are kept in the dark in large glass-jars at a temperature of about $75-80^{\circ} \mathrm{F}$. $\left(23 \cdot 9-26 \cdot 7^{\circ} \mathrm{C}\right.$.). A new colony is started with twelve beetles and twelve larvæ and is provided with the carcass of a rat, or some other small mammal. The colony will take about one month to attain working strength. The skulls to be cleaned are first skinned, brain, eyes and tongue are removed, and then air-dried for twenty-four hours. If the skulls are old, they should be soaked for twenty-four hours in a solution of 'Marmite'. Dermestids will also clean skulls and bones that have been preserved in alcohol, provided that they have been washed in running water to remove as much alcohol as possible. When the bones are clean, they are treated with 0.880 ammonia (diluted with its own volume of water) and then with water. Finally a stream of water is used for removing odd pieces of flesh and cartilage. Full details of this labour-saving technique are given in the paper, which will be welcomed by all museum curators when it is appreciated that by this method forty skulls can be cleaned, soaked and dried in six days for the expenditure of only three man-hours.

\section{Radioactive Tracers in Metallurgical Research}

RADIOACTIVE isotopes of most elements, with suitable characteristics to permit their use as tracers, have now been available, in almost limitless quantities and at relatively low cost, for some four years. Although the biological and medical research workers remain the predominant consumers, the extension of the applications of these useful materials to the industrial and technical fields is steadily increasing. A recent publication by the Ministry of Supply, entitled "Radioactive Tracers in Metallurgical Research" (pp. 56; London : H.M.S.O., 1951; 1s. $9 d$. net) describes their application to one of these fields. The booklet has been written by W. S. Eastwood, W. G. Marley, H. M. Finniston and A. E. Williams, who are all at the Atomic Energy Research Establishment, Harwell, and are actively involved in such studies. In common with most books dealing with radioactive tracers, three out of the four chapters deal with the fundamentals of radioactivity, its measurement and the health hazards presented by the use of radioactive substances. The concise treatment of radioactivity in the first two chapters makes the booklet attractive to all technologists anxious to obtain a necessary minimum knowledge of the fundamentals of tracer methods. The concluding chapter on health hazards should help to convince the cautious industrialist and his research director that tracer investigations may safely be undertaken in most situations if reasonable care be taken, and if competent staff are employed. 